\title{
DESAFIANDO A FILOSOFIA NA EJA: RELATO DE EXPERIÊNCIA NA EDUCAÇÃO
}

\author{
Thamiris Gomes da Costa, (LAGERES) \\ thamiris.gc7@gmail.com
}

\author{
Cristina Novikoff, Universidade Federal de Campina Grande (UFCG) \\ cristinanovikoff@gmail.com
}

PALAVRAS-CHAVE: Educação filosófica, autonomia e valores.

\section{INTRODUÇÃO}

O presente artigo surgiu de uma experiência profissional da Professora Thamiris, com o ensino de educação de jovens e adultos com os alunos de Filosofia e Sociologia, para um trabalho avaliativo do curso de pós-graduação em docência do ensino superior e tecnológico na Faculdade Sul Fluminense.

Quando se foi proposto fazer um artigo a partir da ideia de como você vê a filosofia da educação atual, foi estabelecido uma problematização baseado nos discursos dos próprios alunos participantes desta modalidade de ensino. Na lei de diretrizes e bases da educação nacional LDB, na seção IV que se trata do ensino médio, no artigo 36, parágrafo quarto, fica estabelecido que seja incluída a Filosofia e a Sociologia como disciplinas obrigatórias em todas as séries do ensino médio (Incluído pela Lei $\mathrm{n}^{\circ} 11.684$, de 2008), que determina que as propostas pedagógicas de escolas com organização curricular flexível, não estruturada por disciplinas, deveriam assegurar tratamento interdisciplinar e contextualizado, visando ao domínio de conhecimentos de Filosofia e Sociologia necessários ao exercício da cidadania. E que, no caso de escolas com, no todo ou em parte, organização curricular estruturada por disciplinas, deveriam ser incluídas as de Filosofia e Sociologia.

O presente trabalho pode contribuir para professores que trabalham na EJA, com o intuito de ajudar a refletir nas diversas formas de se trabalhar um conteúdo, de se avaliar o aluno, de como o professor pode fazer a ponte do conteúdo com a experiência de vida de cada um, construir um novo olhar para esta modalidade de ensino, voltando-se para um ensino informal. Acho relevante escrever sobre este assunto, porque além de ser uma área onde na qual a maioria dos professores costumam usar a educação formal, eles acabam trabalhando tradicionalmente os conteúdos e tratando os alunos como crianças crescidas, onde na qual esta modalidade de ensino deve-se ser trabalhando com um certo cuidado, pois os alunos que estão nesta modalidade optam pela mesma em busca de um ensino 
de qualidade mas que também o faça sentido.

O que mais me motivou a escrever sobre este tema foi, a surpresa de encontrar meus alunos atuais tão perdidos quanto aos conteúdos de filosofia, me deparar com as dificuldades encontradas nesta modalidade de ensino, e perceber as necessidades dos alunos para com a disciplina e com a EJA.

Diante desses entendimentos, o objetivo desse artigo é descrever os desafios enfrentados por uma professora atuante na Educação de Jovens e Adultos no que tange ao ensino de Filosofia.

\section{METODOLOGIA}

Esta pesquisa consistiu em um relato de experiência que descreve aspectos vivenciados pela autora, na condição de professora da modalidade de Educação de Jovens e Adultos (EJA). Trata-se de um olhar humanístico e qualitativo, que abordou a problemática desenhada a partir de métodos descritivos e observacionais.

Assim, adotaram-se as Dimensões da pesquisa científica proposta por Novikoff (2010), na qual a investigação é realizada em 5 fases que se articulam durante todo processo. A primeira denominada "epistemológica" que discute o objeto de estudo, sua problematização e hipótese, além de objetivos. Segue a dimensão teórica em que se apresenta as bases de ancoragem teórica. Depois descreve a dimensão técnica, detalhando a metodologia. Na quarta dimensão, a morfológica, é apresentado os resultados. A quinta é a analítico-conclusiva, momento em que se relaciona os resultados as teorias.

No entanto, embora seja utilizado o modelo supracitado, a presente pesquisa trata-se de um relato de experiência que é uma ferramenta da pesquisa descritiva que apresenta uma reflexão sobre uma ação ou um conjunto de ações que abordam uma situação vivenciada no âmbito profissional de interesse da comunidade científica (GIL, 2009). A experiência pedagógica em ação que resultou na redação deste relato acontece como prática profissional da professora em uma cidade localizada na baixada fluminense no Estado do Rio de Janeiro.

Utilizou-se das seguintes técnicas de coleta de dados: observação estruturada (pesquisador participante), participação nas atividades pedagógicas e análise da estrutura física do ambiente. Não foram utilizados dados pessoais dos alunos.

\section{DESCRIÇÕES, RESULTADOS, INTERPRETAÇÕES...}


Graduada em pedagogia pela Universidade do Grande Rio (UNIGRANRIO), sou membro do Laboratório do Grupo de Estudos e Pesquisas em Representações Sociais na/para Formação de Professores - LAGERES. Tenho experiência na área da educação atuando principalmente nos seguintes temas: Corpo, Jovens e Representações Sociais.

Sou professora de (filosofia e sociologia) no Colégio Evangélico Almeida Barros na modalidade EJA no horário noturno.

Os meus alunos são adolescentes e adultos entre 15 a 30 anos, são alunos que optaram por esta modalidade, porque a EJA é uma modalidade de ensino rápida, que é adaptada em uma escola regular, e nesta modalidade eles conseguem recuperar um tempo perdido sequente de um ensino defasado ou até mesmo de acelerar o ensino médio. O ensino é ofertado para ambos os sexos, e o nível de escolaridade deles variam, pois a modalidade EJA inicia desde o ensino fundamental I e vai até a conclusão do ensino médio. Digamos que $60 \%$ dos alunos que buscam o curso, é com o objetivo de finalizar o ensino médio, pois esta escola trabalha com a educação infantil até o fundamental nos turnos da manhã e tarde, então os alunos seguem dentro da instituição para a finalização dos estudos. Mas $40 \%$ são adultos que buscam a EJA no turno da noite, pois o horário se torna mais apropriado para estes estudantes que são trabalhadores, dando assim um apoio para a conclusão dos seus estudos.

Como em todas as modalidades, a EJA é composta por alunos com múltiplas personalidades, mas a grande diferença que faz com que esses alunos sejam diferentes, é que eles já vêm de um ensino defasado, com dificuldades de aprendizagem, e com uma pequena soma de alunos indisciplinados. $\mathrm{O}$ ambiente de trabalho é composto por estruturas adequadas, com professores que conciliam expectativas às dificuldades e necessidades imposta por cada aluno, e temos sempre como objetivo ofertar atividades que possam ser mais adequadas para o universo juvenil e com diferentes atrativos. Nesta modalidade são matriculados em cerca de 80 alunos, considerada uma boa quantidade para se conduzir um bom trabalho. Os alunos são de um comunidade bem próxima a escola, onde se tem uma parcela de acontecimentos relacionados a violência e criminalidade, mas percebesse que este movimento não influencia o comportamento da maioria dos alunos. A grande maioria dos alunos vão a pé para escola, pois eles fazem parte da moradia do entorno da escola, mas alguns alunos vão de ônibus porque já vem do trabalho ou de carros de empresas onde na qual trabalham.

Existem alguns fatores que contribuem para o ingresso do aluno nesta modalidade, e os motivos que ajudam a compor o insucesso escolar são repetência, evasão e outras dificuldades diversas. Compreendendo os movimentos culturais em torno da ideia que movimenta o interesse pelos estudos, Senna afirma que: 
[...] as circunstâncias sociais extra-escolares que definem o modelo cultural dos jovens brasileiros, particularmente os oriundos das grandes massas de cidadãos em estado de exclusão e marginalização, tendem a competir, com vantagem, contra a escola, especialmente por imputar aos alunos um sentimento de não pertencimento à sociedade alfabetizada. (SENNA, 2003, p. 2).

Mesmo com esta visão de que a escola não é algo atrativo, o interesse dos alunos vem se modificando, pois a EJA vem se tornando um espaço de aprendizagem interessante, pois tanto a maturidade profissional e do aluno vem contribuindo para que o aluno garanta uma melhor aprendizagem.

A busca por esta modalidade de ensino vem se tornando grande, pois as escolas vem se modificando para que a educação não seja somente formal, vem se ajustando também estruturalmente para atender as necessidades básicas de um espaço educativo, além da compreensão dos profissionais de educação com relação as necessidades que esta modalidade obtém. As escolas tem se voltado para o aluno da EJA com um olhar mais humano, buscando saber o que sentem e o que pensam, despertando assim a curiosidade dos profissionais que estão envolvidos neste processo.

A filosofia desperta uma atitude crítica podendo ser negativa ou positiva, pois a melhor forma que eu encontrei com que eles fizessem uma assimilação de conteúdo, foi instigá-los à quais são as causas e o sentido de nossas crenças, contextualizando o conteúdo as experiências de cada aluno na sua rotina. A filosofia desperta a sua atitude crítica, pois na maioria das vezes ela remete a momentos de crise no pensamento, na ação e no discurso, pois há uma necessidade de se fundamentar as ideias, a linguagem e as práticas. De acordo com Chaui (2010), assim como cada um de nós, quando possui desejo de saber, vai em direção à atitude filosófica ao perceber contradições, incoerências, ambiguidades ou incompatibilidades entre nossas crenças cotidianas.

Na EJA estou trabalhando a Filosofia com conteúdos, exercícios e reflexões acerca de estimular os alunos a uma visão contextualizada e crítica do conhecimento que eles adquirem. A minha preocupação como professora é fazer com que eles se despertem para o interesse pela filosofia, trilhando o seu caminho de aprendizagem pelos trilhos das indagações e de problemas adquiridos pela experiência em sua rotina. Me atento também para que eles acompanhem a história da filosofia e me permitir trabalhar com a diversidade de disciplinas filosóficas que estão disponíveis nos campos das suas articulações.

Revista de Pesquisa Interdisciplinar, Cajazeiras, n. 2, suplementar, p. 745-750, set. de 2017. 
Venho desmistificando a ideia que a maioria dos alunos vem trazendo a cerca da disciplina, quando na maioria ela é tratada com um assunto que não é de fácil compreensão, ou até mesmo uma disciplina que seria dispensável para compor o quadro de disciplinas do curso. Então eu venho buscando uma abordagem que eu possa apresentar os conteúdos, mas de uma forma que eles possam assimilar os conceitos com os acontecimentos do dia-a-dia deles. Geralmente eles vêm com um conhecimento embaralhado e confuso sobre a filosofia, então eu começo arrumando a história da filosofia, em seguida falo sobre as mudanças que ela sofreu e vem sofrendo de acordo com as épocas e depois venho enfatizando as ideias filosóficas em diversos campos que são determinantes pelas condições que elas se aparecem e se transformam.

E como na educação encontramos meios para se adquirir conhecimento, a educação propicia muito mais que conhecimento e sim meios para processar a capacidade de compreender os processos e suas informações. Vista como um meio de se harmonizar o ambiente escolar, a filosofia vem guiar a organização social. Segundo Porto (2006), uma vez que a política é uma maneira de garantir uma boa vida para os cidadãos, a educação, mesmo quando deve preparar as pessoas para viverem sobre o tipo de estado no qual nasceram, sempre visará as melhores condições de vidas possíveis.

Acredito que os profissionais desta modalidade de ensino precisam carregar consigo a didática, pois é seguindo com ela que as interações, o planejamento das ações, a formulação dos objetivos educacionais, a seleção e organização dos conteúdos curriculares, os procedimentos e os processos de avaliações, possamos juntos acreditar em um ensino que se refletirá no sistema sobre o ideal da educação e da formação humana, pois a didática é a ciência e arte do ensino.

\section{CONSIDERAÇÕES FINAIS}

Com as questões levantadas aqui neste trabalho, faz a autora pensar que a EJA não é uma modalidade de ensino com características fragmentadas, pois além de ser uma modalidade que trabalhe muita mais as questões de teorias com práticas, ela acaba exercendo assim o papel de relacionamento de ensino. Entende-se que a formação ocorre de forma mais panorâmica, adquirindo mais conhecimentos e consolidando os valores trabalhados na prática para que sejam coerentes com a realidade de cada um. 
As complexidades das disciplinas junto com as dificuldades dos jovens vem sendo um motivo para que os profissionais desta modalidade venha propiciar uma difusão de conhecimento com produções para compor um campo educacional com um contexto escolar formal e informal. Os profissionais precisam deixar que os interesses dos alunos sejam instituídos em seu trabalho, para que haja de fato uma representação tradicional de valor social em cima destes conhecimentos, repensando sempre em reestruturar alunos com valores integrados com uma nova base se conhecimento.

\section{REFERÊNCIAS}

BRASIL, Lei de Diretrizes e B. Lei no 9.394/96, de 20 de dezembro de 1996.

CHAUI, Marilena. Filosofia e sociologia: volume único/ Marilena Chaui \& Pérsio Santos de Oliveira. São Paulo: Ática, 2010.

GIL, A. C. Métodos e Técnicas de Pesquisa Social. 6. ed. São Paulo: Atlas, 2009.

HADDAD, Sérgio. Tendências atuais na educação de jovens e adultos. Em Aberto, Brasília, out./dez. 1992, vol. 11, n 4, p. 3-12.

NOVIKOFF, C. Dimensões Novikoff: um constructo para o ensino-aprendizado da pesquisa. In ROCHA, J.G. e NOVIKOFF, C. (orgs.). Desafios da práxis educacional à promoção humana na contemporaneidade. .Rio de Janeiro: Espalhafato Comunicação, p. 211$242,2010$.

PORTO. Leonardo Sartori. Filosofia da Educação. Rio de Janeiro, Jorge Zahar, 2006.

SENNA, Luiz Antonio Gomes. O Planejamento no Ensino Básico \& o compromisso social da educação com o Letramento. Educação \& Linguagem, São José dos Campos, n. 7, p. 200-216,2003.

EDUCAÇÃO DE JOVENS E ADULTOS - EJA: DESAFIOS E PRÁTICAS PEDAGÓGICAS. Mato Grosso: Rodrigues da Silva, n. 9, v. 1, 2013. 